\title{
Quantitation of Six Alternaria Toxins in Infant Foods Applying Stable Isotope Labeled Standards
}

\author{
Marina Gotthardt', Stefan Asam ${ }^{1 *}$, Klara Gunkel ${ }^{1}$, Atefeh Fooladi Moghaddam ${ }^{1,2}$, \\ Elisabeth Baumann ${ }^{1}$, Roland Kietz ${ }^{1}$ and Michael Rychlik ${ }^{1}$
}

${ }^{1}$ Chair of Analytical Food Chemistry, Technical University of Munich, Freising, Germany, ${ }^{2}$ National Nutrition and Food Technology Research Institute, Faculty of Nutrition Sciences and Food Technology, Shahid Beheshti University of Medical Sciences, Tehran, Iran

Alternaria fungi are widely distributed saprophytes and plant pathogens. As pathogens, Alternaria fungi infect crops and vegetables and cause losses in the fields and during postharvest storage. While farmers suffer from declining yields, consumers are endangered by the formation of secondary metabolites, because some of these exhibit a pronounced toxicological potential. The evaluation of the toxicological capabilities is

OPEN ACCESS

Edited by: Alessandra Vincenzi Jager, University of São Paulo, Brazi

Reviewed by:

Karel Dolezal,

Institute of Experimental Botany

(ASCR), Czechia

Bojan Šarkanj,

University North, Croatia

${ }^{*}$ Correspondence:

Stefan Asam

stefan.asam@tum.de

Specialty section

This article was submitted to Fungi and Their Interactions, a section of the journal

Frontiers in Microbiology

Received: 07 November 2018

Accepted: 18 January 2019

Published: 06 February 2019

Citation:

Gotthardt M, Asam S, Gunkel K Moghaddam AF, Baumann E, Kietz $R$ and Rychlik M (2019) Quantitation of Six Alternaria Toxins in Infant Foods Applying Stable Isotope Labeled

Standards. Front. Microbiol. 10:109. doi: 10.3389/fmicb.2019.00109 still ongoing and will contribute to a valid risk assessment. Additionally, data on the incidence and the quantity of Alternaria mycotoxins found in food products is necessary for dietary exposure evaluations. A sensitive LC-MS/MS method for the determination of the Alternaria mycotoxins alternariol $(\mathrm{AOH})$, alternariol monomethylether (AME), tentoxin (TEN), altertoxin I (ATX I), alterperylenol (ALTP), and tenuazonic acid (TA) was developed. $\mathrm{AOH}, \mathrm{AME}$, and TA were quantified using stable-isotopically labeled standards. TEN, ATX I, and ALTP were determined using matrix matched calibration. The developed method was validated by using starch and fresh tomato matrix and resulted in limits of detection ranging from 0.05 to $1.25 \mu \mathrm{g} / \mathrm{kg}$ for starch (as a model for cereals) and from 0.01 to $1.36 \mu \mathrm{g} / \mathrm{kg}$ for fresh tomatoes. Limits of quantification were determined between 0.16 and $4.13 \mu \mathrm{g} / \mathrm{kg}$ for starch and between 0.02 and $5.56 \mu \mathrm{g} / \mathrm{kg}$ for tomatoes. Recoveries varied between 83 and 108\% for starch and between 95 and 111\% for tomatoes. Intra-day precisions were below $4 \%$ and inter-day precisions varied from 3 to $8 \%$ in both matrices. Various cereal based infant foods, jars containing vegetables and fruits as well as tomato products for infants were analyzed for Alternaria mycotoxin contamination ( $n=25)$. TA was the most frequently determined mycotoxin and was detected in much higher contents than the other toxins. AME and TEN were quantified in many samples, but in low concentrations, whereas AOH, ATX I, and ALTP were determined rarely, among which $\mathrm{AOH}$ had higher concentration. Some infant food products were highly contaminated with Alternaria mycotoxins and the consumption of these individual products might pose a risk to the health of infants. However, when the mean or median is considered, no toxicological risk was obvious.

Keywords: Alternaria mycotoxins, stable isotope dilution assay (SIDA), LC-MS/MS, cereal based infant food, tomato products 


\section{INTRODUCTION}

Fungi of the genus Alternaria are ubiquitous microorganisms growing on a wide range of substrates including soil, wall papers, decaying organic material and, most important from both toxicological and economical aspects, agricultural crops used for human and animal nutrition (Ostry, 2008). Infection of plants with Alternaria is commonly believed to occur on the field and many Alternaria species are well-known plant pathogens responsible for a series of plant diseases, e.g., black rot of tomatoes, black and gray rot of citrus fruits and black point of cereals (Logrieco et al., 2009). However, some Alternaria species are also able to grow at low temperature and are responsible for the postharvest decay of fruits and vegetables even at refrigerated storage or transport (Ozcelik et al., 1990). Unrevealing the taxonomy of the genus Alternaria is still a matter of ongoing research. Species differentiation by molecular biology seems to be more promising than the traditional morphologic approach (Zwickel et al., 2018).

The number of fungal secondary metabolites with toxic impact, the so-called mycotoxins, isolated from Alternaria fungi has reached at least 70 compounds up to now (Arcella et al., 2016). They exhibit great structural divergence and are commonly divided into five groups (Figure 1):

- Dibenzo- $\alpha$-pyrones (e.g., alternariol, AOH; alternariolmonomethylether, AME),

- Tetramic acid derivatives (e.g., tenuazonic acid, TA),

- Perylene quinones (e.g., altertoxins I - III, ATX I - III),

- Specific toxins produced by Alternaria alternata subspecies lycopersici (AAL-toxins),

- Miscellaneous structures (e.g., tentoxin, TEN).

The variety of secondary fungal metabolites is further increased by the so-called modified mycotoxins (Rychlik et al., 2014). In case of Alternaria toxins the sulfate (S) conjugates AOH-3-S, AOH-9-S, and AME-3-S were identified as metabolites produced by the fungus itself, whereas the glucose (Glc) conjugates AOH-3-Glc, AOH-9-Glc, AME-3-Glc, and AME-7Glc are regarded as plant metabolites (Soukup et al., 2016). Recently, AOH-9-Glc, AOH-3-S, and AME-3-S have been found for the first time in naturally contaminated tomato sauce for human consumption (Puntscher et al., 2018).

Analytical methods capable to determine this variety of analytes in food commodities are nowadays exclusively based on liquid chromatography coupled to tandem mass spectrometry (LC-MS/MS). In the recent years, methods have been developed to analyze three (Rodríguez-Carrasco et al., 2016), four (Berardis et al., 2018), five (Prelle et al., 2013), six (Noser et al., 2011), eight (Malachová et al., 2014), and even twelve (Zwickel et al., 2016) Alternaria toxins simultaneously, sometimes also including their modified forms (Walravens et al., 2014, 2016; Puntscher et al., 2018).

However, precise quantitation of these different substances still remains challenging, especially in multi-analyte approaches. Stable isotope dilution assays are meanwhile regarded as the gold standard of quantitative analytical methods and are more and more applied also in mycotoxin analysis (Asam and Rychlik, 2015). LC-MS/MS is severely affected by matrix interferences that can manifest themselves either as signal suppression or signal enhancement. By using stable isotope labeled internal standards, these interferences can be optimally minimized. Moreover, losses during sample preparation are also completely compensated for, because respective labeled standards and analytes are chemically indistinguishable and, therefore, show the same recovery throughout all steps of the sample preparation. In case of Alternaria mycotoxins the availability of labeled standards is still limited. So far, only the chemical syntheses of labeled AOH and AME (Asam et al., 2009; Liu and Rychlik, 2015), TEN (Liu and Rychlik, 2013), and TA (Asam et al., 2011b; Lohrey et al., 2013) and the biochemical isolation of labeled $\mathrm{AOH}$, AME, altenuene (ALT), altenuisol (AS), ATX I - III, ALTP, and stemphyltoxin III (STTX III) (Liu and Rychlik, 2015) have been described.

The toxicity of Alternaria toxins has not yet been clarified in detail for all substances and is still a matter of ongoing research. $\mathrm{AOH}$ and $\mathrm{AME}$ are believed to be mutagenic because of their genotoxic effects in vitro (Brugger et al., 2006). On a molecular basis, $\mathrm{AOH}$ has been shown to interact with topoisomerases I and II with effects that have been described as "poisoning" (Fehr et al., 2009). Further research revealed that besides $\mathrm{AOH}$, also AME, ATX I, ATX II, and ALTP are able to provoke these effects (Jarolim et al., 2016). Mutagenicity of ATX I, II, and III has long been known (Stack and Prival, 1986), but recently ATX II was identified as the major mutagen produced by Alternaria (Fleck et al., 2012; Schwarz et al., 2012), although the mode of mutagenic action of the latter is not clear yet (Fleck et al., 2016). TA is an acutely toxic substance with oral $\mathrm{LD}_{50}$ values between 81 and $225 \mathrm{mg} / \mathrm{kg}$ body weight for mice (Miller et al., 1963; Smith et al., 1968). TA inhibits protein biosynthesis by suppressing the release of new proteins from the ribosome (Shigeura and Gordon, 1963). Potentially, it is produced as virulence factor to facilitate colonization of the fungus on plants (Kang et al., 2017). TEN is considered as a phytotoxin, inhibiting photophosphorylation, and inducing chlorosis (Arntzen, 1972).

The Panel on Contaminants in the Food Chain (CONTAM) of the European Food Safety Authority (EFSA) evaluated the risks for public health related to Alternaria toxins in food in the year 2011 (EFSA, 2011). Their assessment was based on the threshold of toxicological concern (TTC) concept (Kroes et al., 2004) due to limited toxicity data for the Alternaria toxins. Although the panel also faced limited occurrence data, they estimated the critical TTC values to be exceeded by $\mathrm{AOH}$ and AME, but not by TEN and TA. In 2016, the EFSA reported a dietary exposure assessment of Alternaria toxins (Arcella et al., 2016). Compared to 2011, similar (AOH) or higher (AME, TEN, TA) exposures were estimated. Cereals and tomato based products were the main origin of Alternaria toxin intake and it was noted that infants were the population group with the highest dietary exposure.

In the year 2012, we conducted a survey about the contamination of infant food with the Alternaria mycotoxin TA. At this time, we found extremely high contamination of infant food samples based on millet (Asam and Rychlik, 2013). 


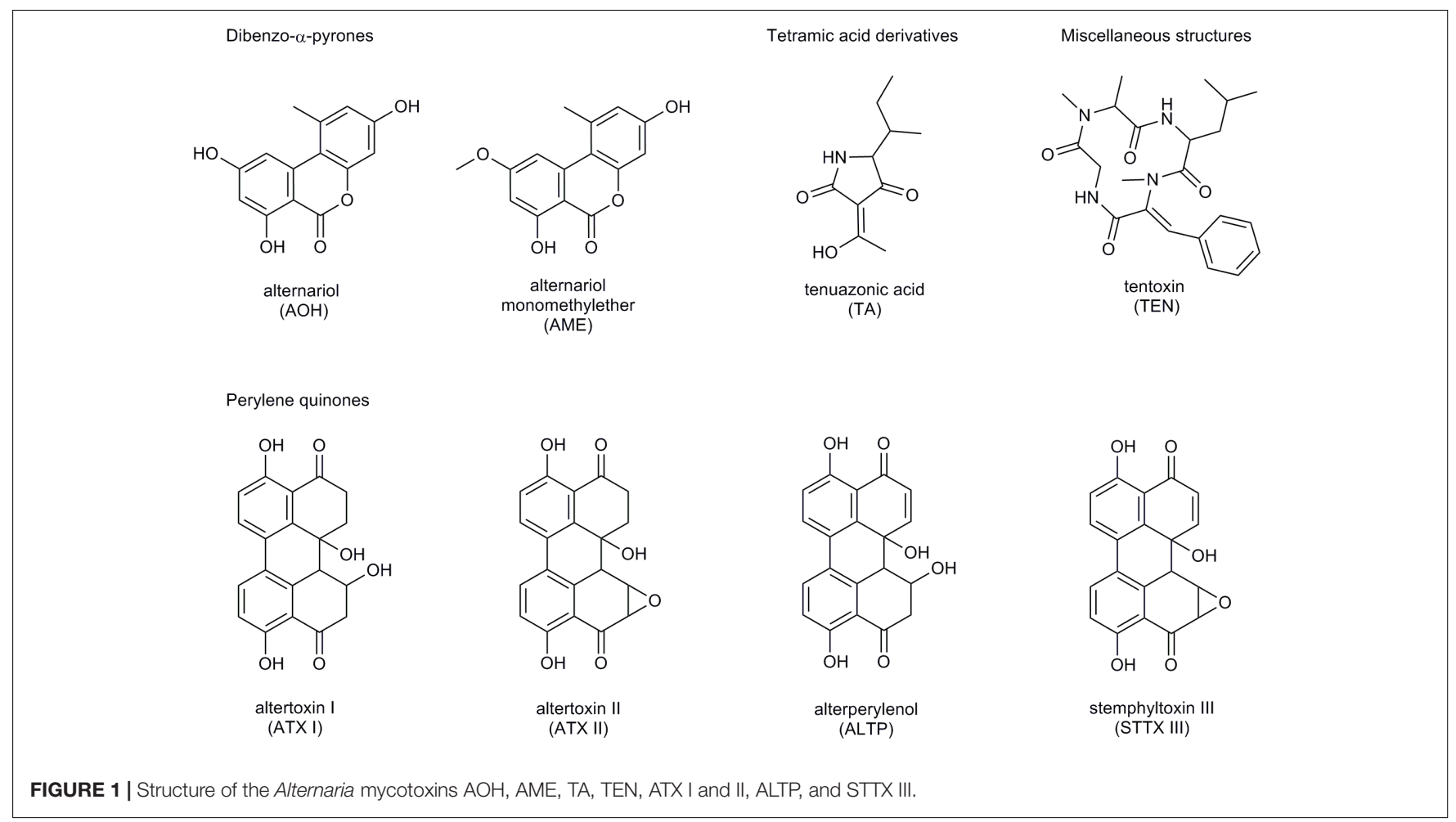

After toxicological evaluation, infant foods were regarded as a potential health hazard if a warning limit of $500 \mu \mathrm{g} / \mathrm{kg}$ of TA was exceeded (Rychlik et al., 2016). Few other studies dealt with this topic so far. In one study from Canada, $\mathrm{AOH}$ and AME were detected in 27 out of 30 samples of cereal-based infant food with maximum values of $4.4 \mu \mathrm{g} / \mathrm{kg}(\mathrm{AOH})$ and $9.0 \mu \mathrm{g} / \mathrm{kg}$ (AME) (Scott et al., 2012).

However, in our study in 2012 we were not able to include the other Alternaria toxins into the analytical scope due to limited sensitivity of the LC-MS equipment. Therefore, the aim of the present study was the development of a new method for the six Alternaria toxins AOH, AME, TA, TEN, ATX I, and ALTP and to apply this method to infant food in order to gain further insight in the actual contamination situation of infant food with Alternaria toxins.

\section{MATERIALS AND METHODS}

\section{Chemicals and Reagents}

Analytical standards of AOH, AME, TA, and TEN were obtained from Sigma-Aldrich (Steinheim, Germany). ATX I, ATX II, ALTP, and STTX III were biosynthesized, purified by preparative HPLC and characterized by mass spectrometry (MS) and nuclear resonance spectroscopy (NMR) as reported earlier (Liu and Rychlik, 2013). TA was released from its commercial copper salt as described in the literature (Shephard et al., 1991; Siegel et al., 2009). The stable isotopically labeled standards $\left[{ }^{2} \mathrm{H}_{4}\right]-\mathrm{AOH}$ and $\left[{ }^{2} \mathrm{H}_{4}\right]$-AME were synthesized according to the literature (Asam et al., 2009). $\left[{ }^{13} \mathrm{C}_{6},{ }^{15} \mathrm{~N}\right]$-TA was prepared in our laboratory as published (Asam et al., 2011b). The labeled standards were also chromatographically purified and characterized by MS and NMR studies.

Formic acid $(\geq 98 \%)$ was obtained from Sigma-Aldrich (Steinheim, Germany). Ammonium formate for mass spectrometry $(\geq 99.0 \%)$ was purchased from Sigma-Aldrich (Bellefonte, PA, United States). Ammonia solution (25\%, for LC-MS) and starch (high purity) were obtained from Merck KGaA (Darmstadt, Germany). Acetonitrile (analytical grade), methanol (analytical grade), water (analytical and LC-MS grade), and isopropanol (LC-MS grade) were received from VWR International GmbH (Ismaning, Germany). Acetonitrile (LC-MS grade) was obtained from Carl Roth GmbH \& Co., KG (Karlsruhe, Germany). Methanol (LC-MS grade) was purchased from Honeywell ${ }^{\mathrm{TM}}$ Riedel-de Häen ${ }^{\mathrm{TM}}$ (Seelze, Germany).

\section{Preparation of Stock Solutions and Calibration Standards}

Stock solutions of unlabeled and labeled Alternaria mycotoxins were prepared in concentrations ranging from 10 to $100 \mu \mathrm{g} / \mathrm{mL}$ in acetonitrile $(\mathrm{AOH}, \mathrm{AME}$, and TEN) or methanol (ATX I, ALTP, and TA). The stock solutions were further diluted for sample preparations and method validations. All solutions were stored at $-20^{\circ} \mathrm{C}$ in the dark. The concentrations of solutions were confirmed by UV spectrometry (Genesys, 10S, UV-Vis spectrophotometer, Thermo Fisher Scientific, Madison, WI, United States) using published extinction coefficients (Zwickel et al., 2016). However, ATX II and STTX III were available only in amounts that were not detectable by UV-VIS and, therefore, were only qualitatively included in the method. 


\section{LC-MS/MS Analysis}

The chromatographic separation of the analytes was performed on a Shimadzu Nexera X2 UHPLC system (Shimadzu, Kyoto, Japan). The LC-parameters for AOH, AME, TEN, ATX I, ATX II, STTX III, and ALTP were adopted from Liu and Rychlik (2013, 2015). A HyperClone BDS-C18 column (150 × $3.2 \mathrm{~mm}, 3 \mu \mathrm{m}, 130 \AA$, Phenomenex, Aschaffenburg, Germany) protected by a C18-guard column $(4 \times 2.0 \mathrm{~mm}$ ID, Phenomenex, Aschaffenburg, Germany) served as stationary phase. The column was tempered to $30^{\circ} \mathrm{C}$. The flow rate was set to $0.2 \mathrm{~mL} / \mathrm{min}$. The binary gradient system consisted of acetonitrile/2-propanol/water (solvent A, 17.5/17.5/65, v/v/v) and methanol (solvent B). The mobile phase was held at $0 \% \mathrm{~B}$ for the first $3 \mathrm{~min}$. The gradient raised linearly from 0 to $100 \% \mathrm{~B}$ in the following $19 \mathrm{~min}$ and remained at $100 \% \mathrm{~B}$ for 1 further min. The mobile phase returned to $0 \% \mathrm{~B}$ within the next 2 min and the column was equilibrated for $5 \mathrm{~min} .10 \mu \mathrm{L}$ were used as injection volume. Using an additional valve after the column, the flow was introduced into the mass spectrometer not until 6.9 min after injection to prevent the instrument from matrix contamination.

Due to the different polarity of TA, the mycotoxin had to be analyzed in an additional LC-MS/MS run. The LC-parameters for TA were based on Asam et al. (2013). A Gemini-NX C18 column $(150 \times 4.6 \mathrm{~mm}, 3 \mu \mathrm{m}, 110 \AA ̊$, Phenomenex, Aschaffenburg, Germany) protected by a Gemini-NX C18-guard column ( 4 × $3.0 \mathrm{~mm}$ ID, Phenomenex, Aschaffenburg, Germany) served as stationary phase. The column was tempered to $40^{\circ} \mathrm{C}$. The flow rate was set to $0.5 \mathrm{~mL} / \mathrm{min}$. The binary gradient system consisted of $5 \mathrm{mM}$ ammonium formate (solvent $\mathrm{A}, \mathrm{pH}$ 9) and methanol (solvent B). The mobile phase was held at $5 \% \mathrm{~B}$ for $3 \mathrm{~min}$, raised linearly from 5 to $100 \% \mathrm{~B}$ in $5 \mathrm{~min}$ and remained at $100 \% \mathrm{~B}$ for $2 \mathrm{~min}$. Thereafter, the gradient returned to $5 \% \mathrm{~B}$ within $3 \mathrm{~min}$ and the column was equilibrated for $10 \mathrm{~min}$. The injection volume was $10 \mu \mathrm{L}$. Using an additional valve after the column, the flow was introduced into the mass spectrometer not until 6.5 min after injection to prevent the instrument from matrix contamination.

Using automated column switching and fourfold solvent selection provided by the instrument, both methods could be run in the same sequence.

The LC was coupled to a triple quadrupole ion trap mass spectrometer (LCMS-8050, Shimadzu Corporation, Kyoto, Japan). The instrument operated in the negative electrospray ionization (ESI) mode for all analytes. Parameters for the interface were adjusted as follows: heating gas flow $10 \mathrm{~L} / \mathrm{min}$, nebulizing gas flow $3 \mathrm{~L} / \mathrm{min}$, drying gas flow $10 \mathrm{~L} / \mathrm{min}$, heat block temperature $400^{\circ} \mathrm{C}$, desolvation line temperature $250^{\circ} \mathrm{C}$, interface temperature $300^{\circ} \mathrm{C}$, interface voltage $4 \mathrm{kV}$ and collision-induced dissociation gas pressure $270 \mathrm{kPa}$. The mass spectrometer worked in the scheduled multiple reaction monitoring (MRM) mode for MS/MS measurements. The voltages for the fragmentation of each analyte were optimized via direct infusion of standard solutions of AOH, AME, TEN, ATX I, ATX II, ALTP, STTX III, and TA at a concentration of $1 \mu \mathrm{g} / \mathrm{mL}$. Two mass transitions were chosen, one as quantifier and one as qualifier for confirmation. Optimized voltages and collision energies, the retention time as well as the quantifier/qualifier ratio of each analyte are listed in Table 1. The LabSolutions software (Shimadzu, Kyoto, Japan) was utilized for data acquisition and data analysis.

\section{Sample Preparation}

In preliminary experiments, different solvent mixtures consisting of acetonitrile, methanol, and water were tested for ideal mycotoxin extraction from grain matrix. The extraction was optimized by adding different amounts of formic acid and acetic acid as well as the adjustment of the extraction duration. Various cartridges with different sorbent material (hydrophiliclipophilic-balanced (HLB, Waters Corporation, Milford, MA, United States), C18 (Discovery ${ }^{\circledR}$ DSC-18, Supelco, Bellefonte, $\mathrm{PA}$, United States), polyamide (PA, CHROMABOND ${ }^{\circledR}$, Machery-Nagel GmbH \& Co., KG, Düren, Germany), $\mathrm{NH}_{2}$ $\left(\mathrm{CHROMABOND}^{\circledR}\right.$, Machery-Nagel GmbH \& Co., KG, Düren, Germany), and Strata-X (Polymeric reversed phase, Phenomenex, Aschaffenburg, Germany) were tested for the simultaneous purification of Alternaria mycotoxins with special regards to TA. From the results of these experiments the optimized sample preparation method was developed as follows:

One gram of ground and homogenized sample was weighed into a $50 \mathrm{~mL}$ centrifuge tube and the isotopically labeled internal standards were added to the sample $\left(100 \mu \mathrm{L}\right.$ of $\left[{ }^{2} \mathrm{H}_{4}\right]-\mathrm{AOH}$ $(0.1 \mu \mathrm{g} / \mathrm{mL}), 50 \mu \mathrm{L}$ of $\left[{ }^{2} \mathrm{H}_{4}\right]$-AME $(0.1 \mu \mathrm{g} / \mathrm{mL})$ and $100 \mu \mathrm{L}$ of $\left[{ }^{13} \mathrm{C}_{6},{ }^{15} \mathrm{~N}\right]$-TA $\left.(1.0 \mu \mathrm{g} / \mathrm{mL})\right)$. The mycotoxins were extracted by adding $15 \mathrm{~mL}$ of a mixture of acetonitrile/water $(84 / 16 ; v / v)$ and $0.2 \mathrm{~mL}$ of formic acid and horizontal shaking for $30 \mathrm{~min}$ (175 rpm). The sample was centrifuged at room temperature at $1690 \times \mathrm{g}$ for $5 \mathrm{~min}$ and the residue was extracted again as described above. The third extraction step was performed by adding $15 \mathrm{~mL}$ of a mixture of acetonitrile/methanol/water $(50 / 25 / 25 ; v / v / v)$ and $0.3 \mathrm{~mL}$ of formic acid. After $30 \mathrm{~min}$ of horizontal shaking $(175 \mathrm{rpm})$, the sample was filtered. The combined extracts and the filtrate were rotary evaporated to dryness at $40^{\circ} \mathrm{C}$. The residue was reconstituted in $12 \mathrm{~mL}$ of water $(\mathrm{pH}$ 5.5). The mycotoxins were purified by solid phase extraction (Discovery ${ }^{\circledR}$ DSC-C18, $500 \mathrm{mg}, 6 \mathrm{~mL}$, Sigma-Aldrich, Bellefonte, PA, United States). The C18 material was washed with $6 \mathrm{~mL}$ of methanol and conditioned with $6 \mathrm{~mL}$ of water ( $\mathrm{pH}$ 5.5). The sample was completely loaded onto the column. After washing the column with $12 \mathrm{~mL}$ of water, the column was dried under vacuum. The mycotoxins were eluted with $6 \mathrm{~mL}$ of methanol. For TA, an additional elution step with $9 \mathrm{~mL}$ of methanol $+2 \%$ ammonium hydroxide was performed. The eluate was rotary evaporated to dryness at $40^{\circ} \mathrm{C}$. The residue was reconstituted in $1 \mathrm{~mL}$ of methanol/water $(1 / 1 ; v / v)$. Remaining matrix precipitated during night at $-20^{\circ} \mathrm{C}$. The sample was membrane filtered $(0.22 \mu \mathrm{m})$ and analyzed by LC-MS/MS.

Twenty-five infant food samples were collected from various supermarkets and drugstores in Germany. Cereal based infant food samples were either single grain or multi-grain products, containing spelt, oat, millet, rice, and wheat. Jars, containing either vegetables or fruits as well as two tomato products were purchased. 
TABLE 1 | Precursor ions and product ions of the unlabeled and labeled Alternaria mycotoxins, optimized fragmentation conditions, retention times, and quantifier/qualifier ratio.

\begin{tabular}{|c|c|c|c|c|c|c|c|}
\hline Analyte & Precursor ion $m / z$ & Product ion $m / z$ & Q1 Pre-bias [V] & CE [V] & Q3 Pre-bias [V] & Retention time [min] & Ratio quantifier/qualifier* \\
\hline \multirow[t]{2}{*}{ ATXI } & 351.20 & 297.20 & 25 & 28 & 19 & 9.6 & 1.15 \\
\hline & & 314.20 & 27 & 32 & 21 & & \\
\hline \multirow[t]{2}{*}{ ALTP } & 349.30 & 261.25 & 18 & 28 & 15 & 10.2 & 0.74 \\
\hline & & 303.00 & 18 & 19 & 18 & & \\
\hline \multirow[t]{2}{*}{$\mathrm{AOH}$} & 257.30 & 213.00 & 15 & 23 & 12 & 11.4 & 1.27 \\
\hline & & 215.05 & 14 & 24 & 13 & & \\
\hline \multirow[t]{2}{*}[{}^{2}\mathrm{H}_{4}]{$-\mathrm{AOH}$} & 261.30 & 217.00 & 15 & 23 & 12 & 11.4 & 2.09 \\
\hline & & 218.05 & 14 & 24 & 13 & & \\
\hline \multirow[t]{2}{*}{ TEN } & 413.30 & 141.05 & 15 & 23 & 23 & 12.5 & 1.46 \\
\hline & & 271.30 & 15 & 17 & 17 & & \\
\hline \multirow[t]{2}{*}{ ATX $\|$} & 349.40 & 313.25 & 16 & 25 & 12 & 13.6 & 0.45 \\
\hline & & 331.30 & 20 & 15 & 20 & & \\
\hline \multirow[t]{2}{*}{ STTX III } & 347.20 & 329.20 & 17 & 22 & 21 & 15.4 & 1.16 \\
\hline & & 301.10 & 17 & 35 & 18 & & \\
\hline \multirow[t]{2}{*}{ AME } & 271.30 & 256.20 & 20 & 23 & 25 & 18.2 & 3.63 \\
\hline & & 228.20 & 19 & 30 & 13 & & \\
\hline \multirow[t]{2}{*}[{}^{2}\mathrm{H}_{4}]{$-\mathrm{AME}$} & 275.30 & 260.20 & 20 & 23 & 25 & 18.2 & 3.47 \\
\hline & & 232.20 & 19 & 30 & 13 & & \\
\hline \multirow[t]{2}{*}{ TA } & 196.30 & 112.05 & 22 & 26 & 20 & 8.3 & 1.01 \\
\hline & & 139.00 & 14 & 22 & 11 & & \\
\hline \multirow[t]{2}{*}[{}^{13}\mathrm{C}_{6,15}\mathrm{N}]{$-\mathrm{TA}$} & 203.25 & 113.05 & 22 & 26 & 20 & 8.3 & 0.91 \\
\hline & & 142.00 & 14 & 22 & 11 & & \\
\hline
\end{tabular}

* Mean of five injections. The quantifier/qualifier ratios were determined in pure solvents.

\section{Calibration and Quantitation}

$\mathrm{AOH}, \mathrm{AME}$, and TA were quantified using isotopically labeled internal standards, whereas TEN, ATX I, and ALTP were quantified using matrix matched calibration.

For AOH, AME, and TA, calibration functions were obtained by mixing various amounts of analyte (A) with constant amounts of internal standard (IS). The calibration functions ranged from molar ratios $[\mathrm{n}(\mathrm{A}) / \mathrm{n}$ (IS)] of 0.01 to $100(1: 100$, $1: 50,1: 10,1: 5,1: 2,1: 1,2: 1,5: 1,10: 1,100: 1)$. The internal standards for $\mathrm{AOH}$ and AME were $\left[{ }^{2} \mathrm{H}_{4}\right]$-labeled. For TA, the $\left[{ }^{13} \mathrm{C}_{6},{ }^{15} \mathrm{~N}\right]$-labeled isotopologue served as internal standard. The calibration points were measured by LC-MS/MS. The calibration functions were calculated using linear regression after plotting molar ratios $[\mathrm{n}(\mathrm{A}) / \mathrm{n}(\mathrm{IS})]$ against peak area ratios $[A(A) / A(I S)]$. Linearity was confirmed by Mandel's fitting test.

Matrix matched calibrations for TEN, ATX I, and ALTP were performed on two different matrices. Potato starch was spiked with various amounts of TEN $(0.1-100 \mu \mathrm{g} / \mathrm{kg})$, ATX I $(0.4-20 \mu \mathrm{g} / \mathrm{kg})$, and ALTP $(0.6-20 \mu \mathrm{g} / \mathrm{kg})$. Blank tomato puree was spiked with varying amounts of TEN $(0.1-100 \mu \mathrm{g} / \mathrm{kg})$, ATX I $(0.4-20 \mu \mathrm{g} / \mathrm{kg})$, and ALTP $(0.4-$ $20 \mu \mathrm{g} / \mathrm{kg}$ ). After sample preparation, the calibration points were analyzed by LC-MS/MS. The calibration curve was constructed from peak area $[\mathrm{A}(\mathrm{A})]$ against spiked contents of the analyte $[\mathrm{w}(\mathrm{A})]$ and the calibration function was received via linear regression. Linearity of the matrix matched calibration functions was confirmed by Mandel's fitting test.
Mycotoxin contamination in cereal based infant food samples or jars was either calculated by using the respective calibration function (AOH, AME, and TA) or by using the matrix-matched calibration function (TEN, ATX I, and ALTP).

\section{Method Validation}

The sample preparation and the LC-MS/MS method were validated according to Vogelgesang and Hädrich (1998). Potato starch was chosen as surrogate blank matrix for the method validation, because all analyzed grain flours contained Alternaria mycotoxins. To obtain a blank tomato matrix, fresh and sound whole tomatoes were pureed and analyzed by LC-MS/MS to confirm the absence of Alternaria mycotoxins.

For the determination of limits of detection (LODs) and quantitation (LOQs), AOH, AME, TEN, ATX I, ALTP, and TA were spiked to the blank matrices at four different levels, respectively. Potato starch was spiked with $\mathrm{AOH}(1.0,3.0,7.0$, and $10 \mu \mathrm{g} / \mathrm{kg}), \operatorname{AME}(0.1,0.3,0.7$, and $1.0 \mu \mathrm{g} / \mathrm{kg})$, TEN $(0.1,0.4,0.7$, and $1.0 \mu \mathrm{g} / \mathrm{kg})$, ATX I $(0.8,2.0,5.0$, and $8.0 \mu \mathrm{g} / \mathrm{kg})$, ALTP $(0.4$, $1.6,2.8$, and $4.0 \mu \mathrm{g} / \mathrm{kg})$, and TA $(2.5,8.0,16$, and $25 \mu \mathrm{g} / \mathrm{kg})$. Fresh tomatoes were spiked with $\mathrm{AOH}(0.15,0.6,1.0$, and $1.5 \mu \mathrm{g} / \mathrm{kg})$, $\operatorname{AME}(0.015,0.06,0.1$, and $0.15 \mu \mathrm{g} / \mathrm{kg})$, TEN $(0.15,0.6,1.0$, and $1.5 \mu \mathrm{g} / \mathrm{kg})$, ATX I $(0.5,2.0,3.5$, and $5.0 \mu \mathrm{g} / \mathrm{kg})$, ALTP $(0.4$, $1.6,2.8$, and $4.0 \mu \mathrm{g} / \mathrm{kg})$, and TA $(1.5,6.0,10$, and $15 \mu \mathrm{g} / \mathrm{kg})$. Each level was prepared in triplicate. The sample preparation was performed as described above and samples were analyzed by LC-MS/MS.

The recoveries for each mycotoxin were determined in starch and tomato matrix at three different levels, respectively. Potato 
starch was spiked with $\mathrm{AOH}(3.0,7.0$, and $10 \mu \mathrm{g} / \mathrm{kg}), \mathrm{AME}(0.3$, 0.7 , and $1.0 \mu \mathrm{g} / \mathrm{kg})$, TEN $(0.4,0.7$, and $1.0 \mu \mathrm{g} / \mathrm{kg})$, ATX I (2.0, 5.0, and $8.0 \mu \mathrm{g} / \mathrm{kg}), \operatorname{ALTP}(1.6,2.8$, and $4.0 \mu \mathrm{g} / \mathrm{kg})$, and TA $(15,100$, and $200 \mu \mathrm{g} / \mathrm{kg})$. Tomato puree was spiked with $\mathrm{AOH}(0.6,1.0$, and $1.5 \mu \mathrm{g} / \mathrm{kg})$, AME $(0.06,0.1$, and $0.15 \mu \mathrm{g} / \mathrm{kg})$, TEN (0.6, 1.0, and $1.5 \mu \mathrm{g} / \mathrm{kg})$, ATX I (2.0, 3.5, and $5.0 \mu \mathrm{g} / \mathrm{kg}), \operatorname{ALTP}(1.6,2.8$, and $4.0 \mu \mathrm{g} / \mathrm{kg}$ ), and TA $(50,100$, and $200 \mu \mathrm{g} / \mathrm{kg})$. Each level was prepared in triplicate. The samples were prepared as described above and analyzed by LC-MS/MS. The content of toxins in the samples were calculated either using SIDA or matrix matched calibration and the recovery was calculated for each toxin as follows: $\mathrm{R}=$ found amount $[\mu \mathrm{g} / \mathrm{kg}] /$ spiked amount $[\mu \mathrm{g} / \mathrm{kg}]$.

Infant food samples containing Alternaria mycotoxins were analyzed to determine the inter-injection precisions, intraand inter-day precisions. A seven-grain infant food product contained TEN $(23 \mu \mathrm{g} / \mathrm{kg})$, ALTP $(6 \mu \mathrm{g} / \mathrm{kg})$, and TA $(114 \mu \mathrm{g} / \mathrm{kg})$ and was spiked with AOH (10 $\mu \mathrm{g} / \mathrm{kg})$, AME $(1.5 \mu \mathrm{g} / \mathrm{kg})$, and ATX I $(6 \mu \mathrm{g} / \mathrm{kg})$. An organic tomato sauce contained $\mathrm{AOH}$ (75 $\mu \mathrm{g} / \mathrm{kg})$, AME $(9 \mu \mathrm{g} / \mathrm{kg})$, and TA $(490 \mu \mathrm{g} / \mathrm{kg})$ and was spiked with TEN ( $8 \mu \mathrm{g} / \mathrm{kg})$, ATX I (5 $\mu \mathrm{g} / \mathrm{kg})$, and ALTP (6 $\mu \mathrm{g} / \mathrm{kg})$.

The inter-injection precision was determined by multiple injections of one sample $(n=5)$. The intra-day precision was calculated after injecting three samples in triplicate into the LCMS/MS. For the inter-day precision, the samples were prepared in triplicate in 3 weeks and injected in triplicate into the LCMS/MS. The mycotoxin contamination was either calculated by using the respective calibration function $(\mathrm{AOH}, \mathrm{AME}$, and TA) or by using the matrix-matched calibration function (TEN, ATX I, and ALTP).

\section{RESULTS}

\section{Method Development}

The Alternaria mycotoxins AOH, AME, TEN, ATX I, ALTP, and TA were extracted from food samples, purified by solid phase extraction and analyzed by LC-MS/MS. To optimize the extraction of Alternaria mycotoxins from grain matrix, different mixtures of acetonitrile, methanol, and water were tested. Applying only one extraction step resulted in insufficient recoveries of the mycotoxins. Therefore, two additional extraction steps were indispensable to extract the mycotoxins sufficiently. For the first and second extraction, a mixture of acetonitrile/water $(84 / 16 ; v / v)$ and the addition of formic acid showed best extraction sufficiency for most of the mycotoxins. The volume of the extraction solvents was set to $15 \mathrm{~mL}$, on the one hand, to obtain good recoveries and, on the other hand, to save time during evaporation. Especially the extraction of the perylene quinones required a third extraction step. The addition of methanol to the extraction solvent increased the recoveries of the perylene quinones and the solvent mixture was optimized to acetonitrile/methanol/water $(50 / 25 / 25 ; v / v / v)$. The addition of formic acid to the extraction solvent improved in particular the extraction efficiency of the perylene quinones. The mycotoxin extracts were then purified by solid phase extraction. Different solid phases were tested for their matrix reduction and their mycotoxin retention, in particular for their simultaneous retention of TA together with the other Alternaria mycotoxins. Promising results provided only C18, Strata-X and HLB cartridges as all tested mycotoxins were retained sufficiently by these sorbent materials. Due to economic reasons, C18 material was finally chosen as sorbent material for the sample preparation. The Alternaria mycotoxins show different polarity and, therefore, the $\mathrm{pH}$ during the conditioning, sample loading, and elution was optimized with special regards to TA. For optimal retention of TA on C18 during sample loading, the $\mathrm{pH}$ of the sample had to be adjusted to 5.5. Elution of the mycotoxins was performed using $6 \mathrm{~mL}$ of methanol. The recovery of TA was improved by applying a second elution step with methanol containing $2 \%$ of ammonium hydroxide. The amount of sample needed for analysis was also adjusted. Different amounts of sample were weighed into centrifuge tubes and the recovery of mycotoxins was determined. Best recoveries were obtained for $1 \mathrm{~g}$ of sample, as 1.5 or $2 \mathrm{~g}$ of sample needed to be extracted with more solvent. The usage of more solvent would also increase duration of evaporation and, therefore, sample preparation time. Less than one gram of sample might not reflect inhomogeneity of the sample sufficiently. The developed sample preparation method for grains was totally applicable to tomato matrix.

\section{LC-MS/MS Analysis}

The LC-parameters for AOH, AME, TEN, ATX I, ATX II, STTX III, and ALTP were adopted from Liu and Rychlik (2013, 2015). Figure 2 displays LC-MS/MS chromatograms of ATX I, ALTP, AOH, TEN, and AME (A), of the internal standards $\left[{ }^{2} \mathrm{H}_{4}\right]$ $\mathrm{AOH}$ and $\left[{ }^{2} \mathrm{H}_{4}\right]$-AME (B), and of ATX II and STTX III (C). A naturally contaminated infant food in jar, consisting of apple, pear, and cherry, is shown in chromatogram (D). TA was added to the existing chromatographic run but due to different polarity, the retention was unsatisfyingly low. Therefore, TA had to be analyzed in a separate LC-MS/MS run. The LC-parameters for TA were based on Asam et al. (2013). Chromatograms of TA (A) and $\left[{ }^{13} \mathrm{C}_{6},{ }^{15} \mathrm{~N}\right]$-TA (B) are displayed in Figure 3. Chromatogram (C) shows a naturally contaminated seven-grain infant food sample. In Figure 4, $\mathrm{AOH}, \mathrm{AME}$, and $\mathrm{TA}$ are depicted in contents of 1.00, 0.10 , and $2.50 \mu \mathrm{g} / \mathrm{kg}$. The labeled internal standards $\left[{ }^{2} \mathrm{H}_{4}\right]-\mathrm{AOH}$, $\left[{ }^{2} \mathrm{H}_{4}\right]$-AME, and $\left[{ }^{13} \mathrm{C}_{6},{ }^{15} \mathrm{~N}\right]-\mathrm{TA}$ are shown at contents of 10.0 , 5.00 , and $10.0 \mu \mathrm{g} / \mathrm{kg}$. Due to the isotope effect, slight retention time shifts of the deuterated internal standards $\left[{ }^{2} \mathrm{H}_{4}\right]-\mathrm{AOH}$ and $\left[{ }^{2} \mathrm{H}_{4}\right]$-AME compared to the unlabeled analytes $\mathrm{AOH}$ and AME are observed during the chromatographic separation. The mass difference between $\left[{ }^{13} \mathrm{C}\right]$ and $\left[{ }^{12} \mathrm{C}\right]$ is proportionally much lower than between $\left[{ }^{2} \mathrm{H}\right]$ and $\left[{ }^{1} \mathrm{H}\right]$ and, therefore, the retention time shift between $\left[{ }^{13} \mathrm{C}_{6},{ }^{15} \mathrm{~N}\right]$-TA and TA is not as pronounced as for the deuterated standards (Rychlik and Asam, 2008).

The fragmentation of AOH, AME, TEN, ATX I, ATX II, STTX III, ALTP, and TA was optimized by injecting solutions of reference compounds $(1.0 \mu \mathrm{g} / \mathrm{mL})$. Mass transitions of the quantifiers and qualifiers of the analytes were checked for interfering matrix compounds. As the matrix did not overlap with the mass transitions of the analytes, specificity of $\mathrm{AOH}, \mathrm{AME}$, TEN, ATX I, ALTP, and TA was assumed during analysis, but constantly monitored through the quantifier/qualifier ratio. 

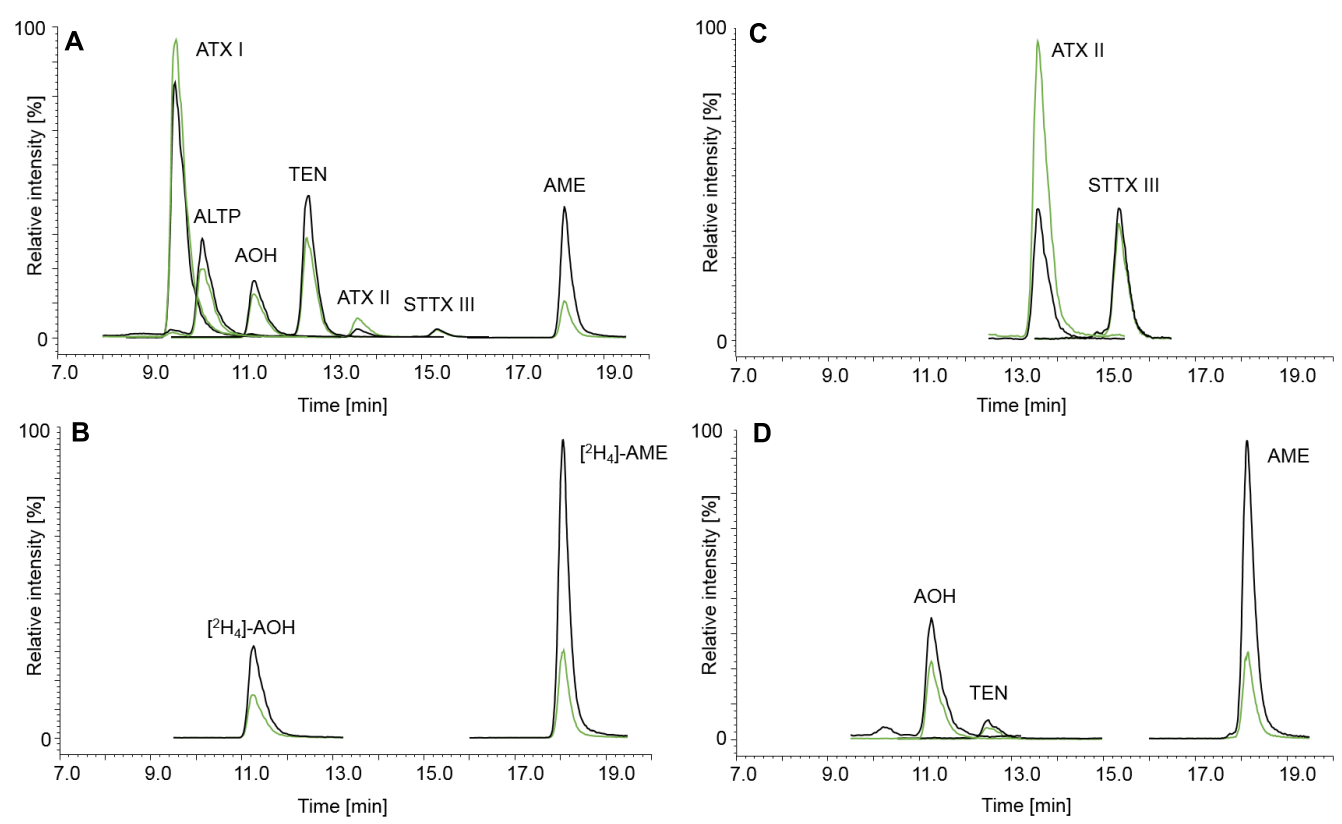

FIGURE 2 | Chromatograms of the Alternaria mycotoxins ATX I (130 $\mu \mathrm{g} / \mathrm{kg})$, ALTP $(20.0 \mu \mathrm{g} / \mathrm{kg})$, AOH $(20.0 \mu \mathrm{g} / \mathrm{kg})$, TEN $(25.0 \mu \mathrm{g} / \mathrm{kg})$, ATX II (approximately $2.00 \mu \mathrm{g} / \mathrm{kg}$, see Section "Preparation of Stock Solutions and Calibration Standards"), STTX III (approximately $3.00 \mu \mathrm{g} / \mathrm{kg}$, see Section "Preparation of Stock Solutions and Calibration Standards"), and AME $(5.00 \mu \mathrm{g} / \mathrm{kg})(\mathbf{A})$ and the isotopically labeled internals standards $\left[{ }^{2} \mathrm{H}_{4}\right]-\mathrm{AOH}(20.0 \mu \mathrm{g} / \mathrm{kg})$ and $\left[{ }^{2} \mathrm{H}_{4}\right]-\mathrm{AME}$ $(5.00 \mu \mathrm{g} / \mathrm{kg})$ (B). Chromatogram (C) shows the standards ATX II (approximately $2.00 \mu \mathrm{g} / \mathrm{kg}$, see Section "Preparation of Stock Solutions and Calibration Standards") and STTX III (approximately $3.00 \mu \mathrm{g} / \mathrm{kg}$, see Section "Preparation of Stock Solutions and Calibration Standards") in more detail. The mycotoxin contamination of an infant food in jar containing apple, pear, and cherry is depicted in chromatogram (D), containing AOH (2.86 $\mu \mathrm{g} / \mathrm{kg})$, TEN $(0.93 \mu \mathrm{g} / \mathrm{kg})$, and AME (1.42 $\mu \mathrm{g} / \mathrm{kg})$. The black and green mass transitions represent the quantifier and qualifier of the analyte and labeled internal standard, respectively.

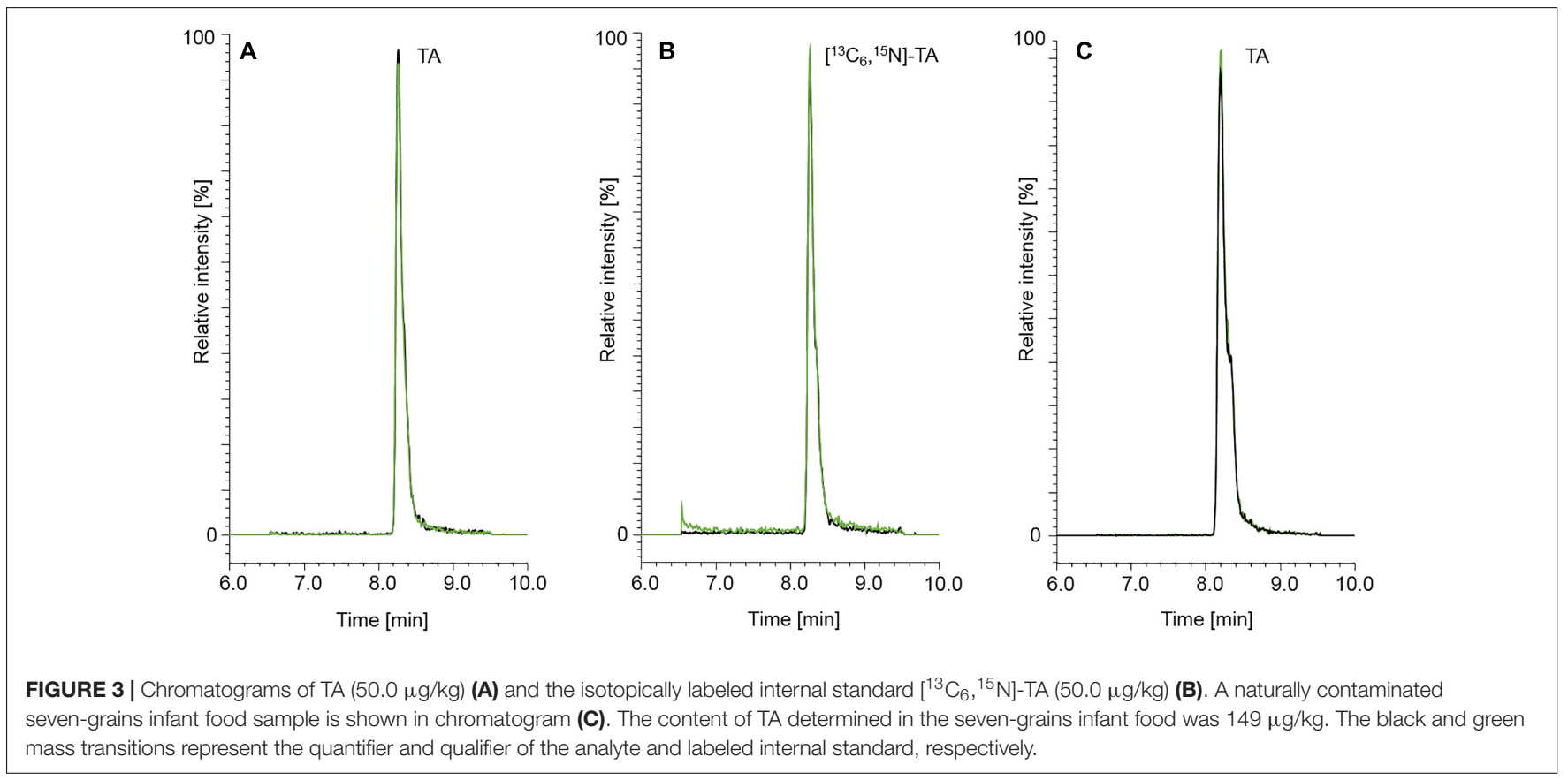

\section{Calibration and Quantification}

Calibration functions of $\mathrm{AOH}, \mathrm{AME}$, and TA were obtained by analyzing mixtures of analyte with the isotopically labeled internal standards. Linearity was confirmed between molar ratios of analyte (A) and internal standard (IS) [n(A)/n(IS)] of 0.01 to 100 , respectively.

Matrix matched calibrations for TEN, ATX I, and ALTP were performed for two different matrices to examine the range 

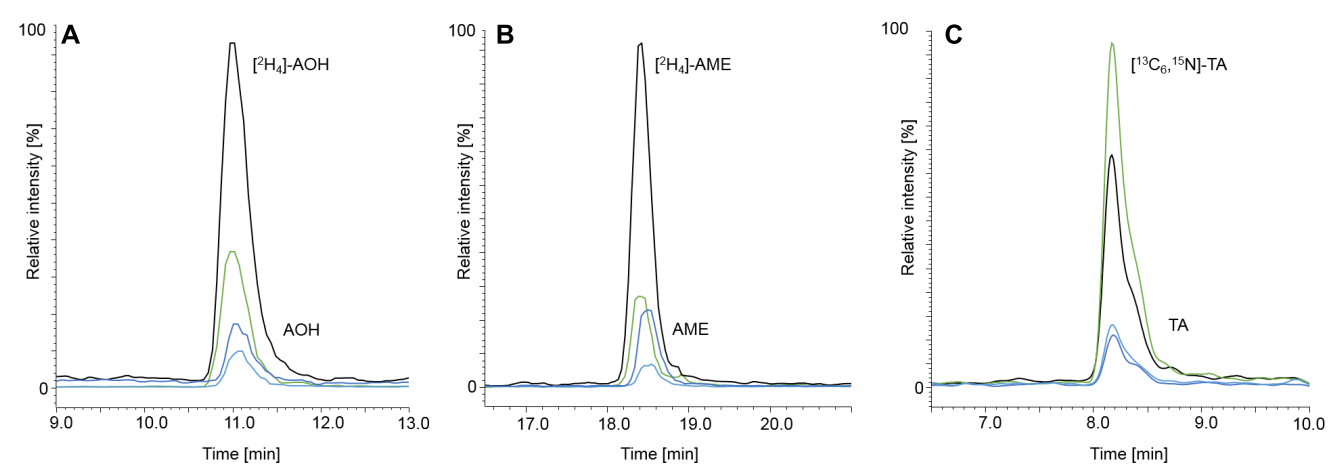

FIGURE 4 | Chromatograms at LOQ level of AOH, $\left[{ }^{2} \mathrm{H}_{4}\right]-\mathrm{AOH}$ (A), AME, $\left[{ }^{2} \mathrm{H}_{4}\right]-\mathrm{AME}$ (B), TA and $\left[{ }^{13} \mathrm{C}_{6},{ }^{15} \mathrm{~N}\right]-\mathrm{TA}$ (C). AOH, AME, and TA are depicted in spiked starch matrix at contents of $1.00,0.10$, and $2.50 \mu \mathrm{g} / \mathrm{kg}$, respectively. The labeled internal standards were added to the matrix at contents of $10.0 \mu \mathrm{g} / \mathrm{kg}$ for $\left[{ }^{2} \mathrm{H}_{4}\right]-\mathrm{AOH}$, $5.00 \mu \mathrm{g} / \mathrm{kg}$ for $\left[{ }^{2} \mathrm{H}_{4}\right]$-AME, and $10.0 \mu \mathrm{g} / \mathrm{kg}$ for $\left[{ }^{13} \mathrm{C}_{6},{ }^{15} \mathrm{~N}\right]-\mathrm{TA}$. The black and the green mass transitions represent the quantifiers and the qualifiers of the labeled standards, whereas the dark blue and light blue mass transitions represent the quantifiers and qualifiers of the analytes, respectively.

of linearity. The linearity of the matrix matched calibration functions was confirmed from 0.1 to $100 \mu \mathrm{g} / \mathrm{kg}$ for TEN, from 0.4 to $20 \mu \mathrm{g} / \mathrm{kg}$ for ATX I, and from 0.6 to $20 \mu \mathrm{g} / \mathrm{kg}$ for ALTP in starch matrix. In tomato puree, the linearity of the calibration functions was confirmed from 0.1 to $100 \mu \mathrm{g} / \mathrm{kg}$ for TEN, from 0.4 to $20 \mu \mathrm{g} / \mathrm{kg}$ for ATX I, and from 0.4 to $20 \mu \mathrm{g} / \mathrm{kg}$ for ALTP.

\section{Method Validation}

Limits of detection (LOD) and limits of quantification (LOQ) were determined according to Vogelgesang and Hädrich (1998). As no cereal flour from the supermarket was free from Alternaria mycotoxins, potato starch was chosen as blank matrix for the method validation. To represent the jar's matrix and the tomato products, fresh tomato puree was chosen as blank matrix for the method validation. AOH, AME, TEN, ATX I, ALTP, and TA were spiked to the blank matrices in triplicate at four different spiking levels. LODs ranged from 0.05 to $1.25 \mu \mathrm{g} / \mathrm{kg}$ in starch matrix (Table 2), and from 0.01 to $1.36 \mu \mathrm{g} / \mathrm{kg}$ in tomato matrix (Table 3). LOQs ranged from 0.16 to $4.13 \mu \mathrm{g} / \mathrm{kg}$ in starch and from 0.02 to $5.56 \mu \mathrm{g} / \mathrm{kg}$ in tomato puree (Tables 2,3).

Recoveries were determined by spiking AOH, AME, TEN, ATX I, ALTP, and TA to the respective blank matrices. The level of spiking complied with contents of the mycotoxins determined in naturally contaminated food products. For the starch matrix, the recoveries ranged from 83 to $108 \%$ (Table 2). For tomato matrix, the recoveries ranged from 95 to $111 \%$ (Table 3 ).

Various precisions (relative standard deviations) of the analytes were calculated (Tables 2,3 ). Inter-injection precisions were determined by repetitive injecting $(n=5)$ a cereal based infant food sample or the tomato soup into the LC-MS/MS instrument. Relative standard deviations ranged from 2 to $3 \%$ in the cereal based product and from 1 to $2 \%$ in the tomato soup. The intra-day and inter-day precisions were determined by preparing one sample in triplicate and in 3 weeks. The calculated intra-day precisions lay between 1 and 3\% in cereals and between 1 and $3 \%$ in the tomato matrix. Inter-day precisions varied from
3 to $7 \%$ in the cereal based infant food and from 3 to $8 \%$ in the tomato soup.

\section{Analysis of Infant Food Samples}

Various cereal based infant food samples $(n=19)$ as well as jars $(n=6)$ were purchased from local drugstores and supermarkets and analyzed for their content of AOH, AME, TEN, ATX I, ALTP, and TA (Table 4). Within the cereal based infant foods, single grain as well as multi-grain products were analyzed. ATX II and STTX III were not detected in any of the infant food samples. The other Alternaria mycotoxins were detected in cereal based infant food above the limit of quantification in 17 out of 19 samples. TA was determined in $89 \%$ of the products with contents above the limit of quantification. The contamination of the latter ranged from 5.66 to $221 \mu \mathrm{g} / \mathrm{kg}$ and exceeded the contents of the other mycotoxins. Single grain products with partially high contamination of TA were millet $(221 \mu \mathrm{g} / \mathrm{kg})$, spelt $(102 \mu \mathrm{g} / \mathrm{kg})$, rice $(109 \mu \mathrm{g} / \mathrm{kg})$, and two multi-grain products (104 and $149 \mu \mathrm{g} / \mathrm{kg}$ ). The median contamination of TA in the cereal based products was $22.0 \mu \mathrm{g} / \mathrm{kg}$. AOH was determined in one spelt and one multi-grain product with contents of 7.17 and $4.73 \mu \mathrm{g} / \mathrm{kg}$. AME was determined in $53 \%$ of all cereal based infant products with contents above the limit of quantification. The contamination of AME ranged from 0.23 to $0.58 \mu \mathrm{g} / \mathrm{kg}$ with a median of $0.23 \mu \mathrm{g} / \mathrm{kg}$, which can be considered as low contamination. Eighty-four percent of all products contained TEN in amounts from 0.18 to $7.53 \mu \mathrm{g} / \mathrm{kg}$. The median was $0.43 \mu \mathrm{g} / \mathrm{kg}$. ATX I was detected in only one wheat infant food sample with a content of $1.52 \mu \mathrm{g} / \mathrm{kg}$. ALTP was detected in one multi-grain product above the limit of quantification with a content of $4.47 \mu \mathrm{g} / \mathrm{kg}$.

Four different purees in jars as well as one tomato sauce and one tomato soup were analyzed for $\mathrm{AOH}, \mathrm{AME}, \mathrm{TEN}$, ATX I, ALTP, and TA contamination (Table 5). Five out of six samples contained Alternaria mycotoxins above the limit of quantification. $\mathrm{AOH}$ and TEN were determined in one jar 
TABLE 2 | Limits of detection, limits of quantification, recoveries, and precisions determined for Alternaria mycotoxins in starch.

\begin{tabular}{|c|c|c|c|c|c|c|c|c|}
\hline \multirow[t]{2}{*}{ Analyte } & \multirow[t]{2}{*}{ LOD $[\mu \mathrm{g} / \mathrm{kg}]$} & \multirow[t]{2}{*}{$\operatorname{LOQ}[\mu \mathrm{g} / \mathrm{kg}]$} & \multicolumn{3}{|c|}{ Recovery [\%] } & \multicolumn{3}{|c|}{ Precision (RSD) [\%] } \\
\hline & & & Level 1 & Level 2 & Level 3 & Inter-injection ( $n=5)$ & Intra-day $(n=3)$ & Inter-day $(n=9)$ \\
\hline $\mathrm{AOH}$ & 0.50 & 1.81 & $101 \pm 6$ & $97 \pm 2$ & $92 \pm 2$ & 2 & 2 & 5 \\
\hline AME & 0.05 & 0.23 & $94 \pm 8$ & $103 \pm 1$ & $108 \pm 5$ & 2 & 2 & 3 \\
\hline TEN & 0.05 & 0.16 & $91 \pm 7$ & $83 \pm 1$ & $83 \pm 2$ & 3 & 3 & 7 \\
\hline ATXI & 0.42 & 1.49 & $101 \pm 6$ & $94 \pm 5$ & $91 \pm 3$ & 2 & 3 & 6 \\
\hline ALTP & 0.31 & 1.03 & $105 \pm 5$ & $94 \pm 2$ & $97 \pm 4$ & 2 & 1 & 5 \\
\hline TA & 1.25 & 4.13 & $95 \pm 2$ & $92 \pm 5$ & $106 \pm 4$ & 2 & 1 & 5 \\
\hline
\end{tabular}

TABLE 3 | Limits of detection, limits of quantification, recoveries, and precisions determined for Alternaria mycotoxins in fresh tomatoes.

\begin{tabular}{|c|c|c|c|c|c|c|c|c|}
\hline \multirow[t]{2}{*}{ Analyte } & \multirow[t]{2}{*}{ LOD $[\mu \mathrm{g} / \mathrm{kg}]$} & \multirow[t]{2}{*}{$L O Q[\mu \mathrm{g} / \mathrm{kg}]$} & \multicolumn{3}{|c|}{ Recovery [\%] } & \multicolumn{3}{|c|}{ Precision (RSD) [\%] } \\
\hline & & & Level 1 & Level 2 & Level 3 & Inter-injection $(n=5)$ & Intra-day $(n=3)$ & Inter-day $(n=9)$ \\
\hline $\mathrm{AOH}$ & 0.16 & 0.55 & $103 \pm 3$ & $95 \pm 9$ & $100 \pm 2$ & 1 & 1 & 3 \\
\hline AME & 0.01 & 0.02 & $111 \pm 1$ & $97 \pm 1$ & $96 \pm 2$ & 1 & 1 & 4 \\
\hline TEN & 0.05 & 0.22 & $101 \pm 3$ & $107 \pm 2$ & $109 \pm 1$ & 1 & 1 & 6 \\
\hline ATXI & 0.19 & 0.76 & $107 \pm 4$ & $101 \pm 2$ & $103 \pm 2$ & 2 & 1 & 4 \\
\hline ALTP & 0.21 & 0.74 & $107 \pm 4$ & $97 \pm 2$ & $100 \pm 1$ & 1 & 3 & 5 \\
\hline TA & 1.36 & 5.56 & $107 \pm 2$ & $99 \pm 1$ & $96 \pm 3$ & 2 & 1 & 8 \\
\hline
\end{tabular}

TABLE 4 | Contents of Alternaria mycotoxins in infant foods based on the cereals indicated.

\begin{tabular}{|c|c|c|c|c|c|c|}
\hline Variety & $\mathrm{AOH}[\mu \mathrm{g} / \mathrm{kg}]$ & AME $[\mu \mathrm{g} / \mathbf{k g}]$ & TEN $[\mu \mathrm{g} / \mathbf{k g}]$ & ATX I $[\mu \mathrm{g} / \mathrm{kg}]$ & ALTP $[\mu \mathrm{g} / \mathrm{kg}]$ & $\mathrm{TA}[\mu \mathrm{g} / \mathrm{kg}]$ \\
\hline Wheat 1 & - & $(0.15)^{a}$ & - & - & - & $(2.62)^{a}$ \\
\hline Wheat 2 & $(0.76)^{a}$ & $0.37 \pm 0.13$ & $0.60 \pm 0.06$ & $1.52 \pm 0.11$ & - & $8.38 \pm 0.28$ \\
\hline Wheat 3 & - & $0.33 \pm 0.11$ & $1.29 \pm 0.09$ & - & - & $10.2 \pm 0.1$ \\
\hline Wheat 4 & - & - & $(0.06)^{\mathrm{a}}$ & - & - & - \\
\hline Oat 1 & - & $(0.08)^{\mathrm{a}}$ & $(0.10)^{a}$ & - & - & $22.0 \pm 0.5$ \\
\hline Oat 2 & - & $0.25 \pm 0.01$ & $0.18 \pm 0.02$ & - & - & $8.54 \pm 0.75$ \\
\hline Millet 1 & - & $(0.06)^{a}$ & $0.33 \pm 0.04$ & - & - & $43.6 \pm 0.2$ \\
\hline Millet 2 & $(1.01)^{a}$ & $0.35 \pm 0.05$ & $0.86 \pm 0.03$ & - & - & $221 \pm 2$ \\
\hline Spelt 1 & - & $(0.05)^{\mathrm{a}}$ & $0.43 \pm 0.01$ & - & - & $102 \pm 1$ \\
\hline Spelt 2 & $7.17 \pm 0.65$ & $0.27 \pm 0.07$ & $0.41 \pm 0.15$ & $(0.67)^{a}$ & - & $49.6 \pm 3.0$ \\
\hline Spelt 3 & $(0.67)^{a}$ & $(0.05)^{a}$ & $0.72 \pm 0.08$ & - & - & $23.7 \pm 0.5$ \\
\hline Rice 1 & - & $0.58 \pm 0.24$ & $2.22 \pm 0.36$ & - & - & $109 \pm 1$ \\
\hline rice 2 & $(0.67)^{a}$ & $(0.13)^{\mathrm{a}}$ & $0.30 \pm 0.04$ & - & - & $10.1 \pm 0.1$ \\
\hline Multi-grain 1 & $4.73 \pm 0.04$ & $0.55 \pm 0.21$ & $0.41 \pm 0.03$ & - & - & $12.4 \pm 0.1$ \\
\hline Multi-grain 2 & - & - & $0.21 \pm 0.02$ & - & - & $5.66 \pm 0.31$ \\
\hline Multi-grain 3 & - & $0.23 \pm 0.06$ & $0.62 \pm 0.17$ & - & - & $66.0 \pm 0.9$ \\
\hline Multi-grain 4 & $(1.37)^{a}$ & $0.56 \pm 0.13$ & $0.60 \pm 0.06$ & - & - & $6.15 \pm 0.49$ \\
\hline Multi-grain 5 & - & $0.46 \pm 0.08$ & $2.08 \pm 0.55$ & $(0.81)^{a}$ & - & $104 \pm 1$ \\
\hline Multi-grain 6 & - & $0.07^{a}$ & $7.53 \pm 0.97$ & - & $4.47 \pm 0.31$ & $149 \pm 1$ \\
\hline Mean $^{b}$ & 0.89 & 0.24 & 1.00 & 0.17 & 0.24 & 50.2 \\
\hline Median $^{b}$ & 0 & 0.23 & 0.43 & 0 & 0 & 22.0 \\
\hline
\end{tabular}

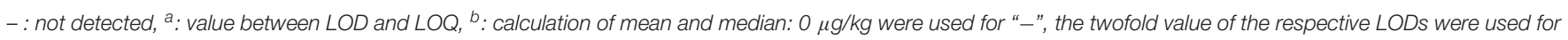
values below the LOQs.

with contents of 2.86 and $0.44 \mu \mathrm{g} / \mathrm{kg}$. AME was determined in contents ranging from 0.04 to $7.56 \mu \mathrm{g} / \mathrm{kg}$ with a median of $0.14 \mu \mathrm{g} / \mathrm{kg}$. TA was detected in two of the purees at a mean of $4.95 \mu \mathrm{g} / \mathrm{kg}$. ATX I, ATX II, ALTP, and STTX III were not detected in any of the puree products. $8.73 \mu \mathrm{g} / \mathrm{kg}$ of TA were quantified in the tomato soup, whereas the tomato sauce contained high amounts of $\mathrm{AOH}(54.2 \mu \mathrm{g} / \mathrm{kg})$, AME $(7.56 \mu \mathrm{g} / \mathrm{kg})$, and TA $(505 \mu \mathrm{g} / \mathrm{kg})$. 
TABLE 5 | Contents of Alternaria mycotoxins in puree infant food consisting of vegetables and fruits, and in tomato products.

\begin{tabular}{|c|c|c|c|c|c|c|}
\hline Variety & $\mathrm{AOH}[\mu \mathrm{g} / \mathrm{kg}]$ & AME $[\mu \mathrm{g} / \mathrm{kg}]$ & TEN $[\mu \mathrm{g} / \mathrm{kg}]$ & ATX I $[\mu \mathrm{g} / \mathrm{kg}]$ & ALTP $[\mu \mathrm{g} / \mathrm{kg}]$ & $\mathrm{TA}[\mu \mathrm{g} / \mathrm{kg}]$ \\
\hline Tomato sauce & $54.2 \pm 2.8$ & $7.56 \pm 0.72$ & $0.44 \pm 0.09$ & - & - & $505 \pm 26$ \\
\hline Apple-pear-cherry & $2.86 \pm 0.99$ & $1.42 \pm 0.07$ & $0.93 \pm 0.02$ & - & - & $(5.38)^{a}$ \\
\hline Pumpkin and potato & $(0.32)^{a}$ & - & - & - & - & - \\
\hline Cherry and banana & $(0.17)^{a}$ & $0.14 \pm 0.07$ & - & - & - & $(4.51)^{a}$ \\
\hline Vegetable & - & $0.04 \pm 0.02$ & - & - & - & - \\
\hline Tomato soup & - & $0.04 \pm 0.01$ & - & - & - & $8.73 \pm 0.03$ \\
\hline Mean $^{b}$ & 9.62 & 1.53 & 0.23 & - & - & 86.5 \\
\hline Median $^{b}$ & 0.32 & 0.14 & 0 & - & - & 2.51 \\
\hline
\end{tabular}

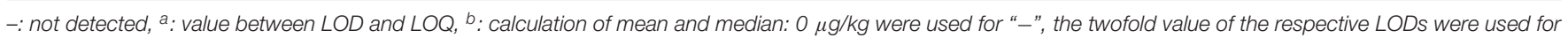
values below the LOQs.

\section{DISCUSSION}

\section{Method Validation}

LODs and LOQs determined in our method validation process are in accordance with the LODs and LOQs of methods recently reported in the literature. Liu et al. determined LODs and LOQs in starch matrix of 0.088 to $0.36 \mu \mathrm{g} / \mathrm{kg}$ and 0.27 to $1.1 \mu \mathrm{g} / \mathrm{kg}$ for AOH, AME, ATX I, and ALTP (Liu and Rychlik, 2015). For TA, low LODs and LOQs were achieved for both matrices. As the sample preparation and sample cleanup was extensively optimized for TA, derivatization with 2,4dinitrophenylhydrazine (Siegel et al., 2009; Asam et al., 2011b) was not necessary to obtain low LODs and LOQs.

Zwickel et al. calculated LOQs of AOH, AME, TEN, ATX I, and TA of 0.4 up to $0.9 \mu \mathrm{g} / \mathrm{kg}$ in tomato juice (Zwickel et al., 2016). Puntscher et al. recently achieved LODs and LOQs in tomato sauce of $0.05-6$ and $0.1-12 \mu \mathrm{g} / \mathrm{kg}$ with a dilute and shoot approach (Puntscher et al., 2018).

In our method validation process, recoveries ranged from 83 to $111 \%$ for AOH, AME, TEN, ATX I, ALTP, and TA in both matrices. To achieve these good recoveries, the samples needed to be extracted three times with different solvent mixtures. Performing only one extraction step resulted in losses of analytes between 19 and $42 \%$. AOH, AME, and TA were quantified using stable isotopically labeled internal standards and the recoveries ranged from 92 to $111 \%$. Quantification of TEN, ATX I, and ALTP by matrix matched calibrations resulted in a slightly lower recovery rate for TEN at two spiking levels. For ATX I and ALTP, matrix matched calibrations compensated for analyte losses during sample preparation and recoveries varied between 91 and $109 \%$.

Inter-injection, intra- and inter-day precisions were determined for cereal and tomato based products and resulted in precisions below $4 \%$ for inter-injection and intra-day precisions and below $9 \%$ for inter-day precisions. Zwickel et al. calculated intra- and inter-day precisions varying from 3.6 to $9.2 \%$ and 4.0 to $10.7 \%$ in tomato juice (Zwickel et al., 2016). In contrast to this, a recently published dilute and shoot approach revealed intra-day precisions varying from 9 to $34 \%$ at low concentrations and from 3 to $16 \%$ at high concentrations in tomato sauce. In wheat flour, intra-day precisions ranged from 11 to $83 \%$ at low concentrations and from 3 to $11 \%$ at high concentrations (Puntscher et al., 2018).

\section{Analysis of Infant Food Samples}

In our survey, cereal based infant products were frequently contaminated with Alternaria mycotoxins, especially AME, TEN, and TA. While the level of contamination of AME and TEN is mainly rather low, high variations in the content of TA were observed with a mean content of $50.2 \mu \mathrm{g} / \mathrm{kg}$ and a median content of $22.0 \mu \mathrm{g} / \mathrm{kg}$. The variations were detected not only among different grain varieties but also within one grain variety. Grain products such as oat flakes, wheat flour, rye flour, and maize grit have been analyzed already by Asam et al., who found a median content of TA of $16 \mu \mathrm{g} / \mathrm{kg}$ (Asam et al., 2012). In a subsequent study, Asam et al. quantified the toxin in various infant cereal products (Asam and Rychlik, 2013). The products comprising of wheat, oats, rye, spelt, maize, and barley contained TA in amounts of $8-30 \mu \mathrm{g} / \mathrm{kg}$. Four different millet products were contaminated with high amounts of TA ranging from 130 to $1200 \mu \mathrm{g} / \mathrm{kg}$ (Asam and Rychlik, 2013). In our present survey, two millet infant cereals were analyzed and contained 43.6 and $221 \mu \mathrm{g} / \mathrm{kg}$ of TA. Two of the multi-grain products contained millet flour and were contaminated with 66.0 and $140 \mu \mathrm{g} / \mathrm{kg}$ of TA. In total, none of the analyzed infant food samples in our survey reached the high contamination of millet with TA of up to $1200 \mu \mathrm{g} / \mathrm{kg}$, which were determined by Asam and Rychlik (2013). It has to be noted that we undertook all effort to collect more millet based infant food samples, but in contrast to 2012 the availability of this product group was very limited. However, as far as it can be deduced from the analyzed samples, the manufactures obviously optimized their quality control and none of the products exceeded the warning limit of $500 \mu \mathrm{g} / \mathrm{kg}$, which is beneficial for the consumer's health. As the multi-grain products contained various grains, millet cannot be identified as the sole source of TA contamination.

In 2012, Scott et al. also quantified AOH and AME in various infant foods from Canada. In their survey, single grain as well as 
multi-grain products were analyzed and revealed $0.5-4.4 \mu \mathrm{g} / \mathrm{kg}$ of $\mathrm{AOH}$ and $0.5-2.0 \mu \mathrm{g} / \mathrm{kg}$ of AME (Scott et al., 2012). For Europe, the EFSA assessed the dietary exposure of the European population to Alternaria mycotoxins. The mean contamination of wheat grain, spelt grain, and oats were $0.3-39.7 \mu \mathrm{g} / \mathrm{kg}$ of $\mathrm{AOH}, 0.03-7.1 \mu \mathrm{g} / \mathrm{kg}$ of AME, $0.03-3.8 \mu \mathrm{g} / \mathrm{kg}$ of $\mathrm{TEN}$, and $2.6-168.7 \mu \mathrm{g} / \mathrm{kg}$ of TA (Arcella et al., 2016). In a recently published survey, nine wheat flours from the Austrian market were analyzed for free and modified Alternaria mycotoxins. No Alternaria mycotoxin could be detected above the respective limits of quantification (Puntscher et al., 2018). In contrast to this, AOH, AME, TEN, ATX I, and TA were detected in two out of four wheat based cereal samples in our study.

A previous survey by our group analyzed various cereal flours for their content of ATX I, ALTP, ATX II, AOH, AME, and TEN (Liu and Rychlik, 2015). ATX I was determined in three different flours with contents of 2.4-4.7 $\mu \mathrm{g} / \mathrm{kg}$. ALTP was determined in one sample $(0.87 \mu \mathrm{g} / \mathrm{kg})$. AOH, AME, and TEN were quantified in contents ranging from 1.1 to $23,0.31$ to 0.34 , and 1.6 to $6.0 \mu \mathrm{g} / \mathrm{kg}$.

Apart from the cereal products we analyzed four different purees in jars, one tomato sauce and one tomato soup. The results of the tomato sauce were striking, because it contained up to $54.2 \mu \mathrm{g} / \mathrm{kg} \mathrm{AOH}, 7.56 \mu \mathrm{g} / \mathrm{kg}$ AME, and $505 \mu \mathrm{g} / \mathrm{kg}$ TA. When comparing these unexpectedly high contents of mycotoxins to data from the literature, similarly high concentrations amounting to $25 \mu \mathrm{g} / \mathrm{kg}$ of $\mathrm{AOH}$ and $5.3 \mu \mathrm{g} / \mathrm{kg}$ of AME have been reported in a triple concentrated tomato paste (Asam et al., 2011a). Analyzing TA in various tomato products, Asam et al. detected 363 to $909 \mu \mathrm{g} / \mathrm{kg}$ of TA in tomato paste (Asam et al., 2011b). The tomato paste was triple concentrated and, therefore, the raw material could be estimated to have contained 120 to $300 \mu \mathrm{g} / \mathrm{kg}$. The tomato sauce in our survey is ready to use and consists of $65 \%$ of tomatoes as well as $13 \%$ of concentrated tomato paste. Therefore, it can be assumed that the concentrated tomato paste might be the reason for the high mycotoxin contamination in the final tomato sauce product. In a recent assessment, the EFSA estimated the chronic dietary exposure of humans to Alternaria mycotoxins (Arcella et al., 2016). Lower and upper bound mean concentrations ranged from 0.0 to $5.7 \mu \mathrm{g} / \mathrm{kg}$ of $\mathrm{AOH}$, from 0.0 to $1.0 \mu \mathrm{g} / \mathrm{kg}$ of AME, from 0.0 to $3.9 \mu \mathrm{g} / \mathrm{kg}$ of TEN, and from 34 to $54 \mu \mathrm{g} / \mathrm{kg}$ of TA. Tomato puree contained up to $6.5 \mu \mathrm{g} / \mathrm{kg} \mathrm{AOH}$, $1.9 \mu \mathrm{g} / \mathrm{kg}$ AME, $3.3 \mu \mathrm{g} / \mathrm{kg}$ TEN, and $113 \mu \mathrm{g} / \mathrm{kg}$ TA (EFSA, 2011). These data are well in line with those of our previously analyzed puree infant food in jars that contained TA in amounts ranging from 1.0 up to $78 \mu \mathrm{g} / \mathrm{kg}$. Tomato soup contained $25 \mu \mathrm{g} / \mathrm{kg}$ of TA (Asam and Rychlik, 2013). The TA content of $78 \mu \mathrm{g} / \mathrm{kg}$ in banana and cherry jars from 2012 (Asam and Rychlik, 2013) was not reached in this study, as the TA content in our banana and cherry jar was only $4.51 \mu \mathrm{g} / \mathrm{kg}$.

In a recently published survey (Puntscher et al., 2018), various tomato sauces $(n=12)$ were analyzed for free and modified Alternaria mycotoxins. AOH was detected in two samples above the LOQ (1.4 and $20.2 \mu \mathrm{g} / \mathrm{kg}$ ). AME and TEN were determined in one sample and the content was 4.0 and $0.6 \mu \mathrm{g} / \mathrm{kg}$, respectively. TA was quantified in eight samples with contents ranging from 42 to $323 \mu \mathrm{g} / \mathrm{kg}$ (Puntscher et al., 2018). Although the AOH content of $20.2 \mu \mathrm{g} / \mathrm{kg}$ in one of the tomato sauces was high, the tomato sauce for children in our survey exceeded this value by a factor of two.

From the Swiss market, Noser et al. analyzed 85 tomatoes and tomato products and reported even higher toxin contents. One tomato puree contained $790 \mu \mathrm{g} / \mathrm{kg} \mathrm{TA}, 30 \mu \mathrm{g} / \mathrm{kg} \mathrm{AOH}$, $8 \mu \mathrm{g} / \mathrm{kg} \mathrm{AME}$, and $2 \mu \mathrm{g} / \mathrm{kg}$ TEN. In tomato sauces and soups 4$144 \mu \mathrm{g} / \mathrm{kg}$ of TA, $4-10 \mu \mathrm{g} / \mathrm{kg}$ of $\mathrm{AOH}$, and $1-4 \mu \mathrm{g} / \mathrm{kg}$ of AME were determined. However, the group did not analyze tomato products which are intended for infant consumption (Noser et al., 2011).

Walravens et al. analyzed 28 tomato sauces and determined $\mathrm{AOH}$ in contents up to $41.6 \mu \mathrm{g} / \mathrm{kg}$, AME up to $3.8 \mu \mathrm{g} / \mathrm{kg}$, and TA up to $330.6 \mu \mathrm{g} / \mathrm{kg}$, which is well in line with our findings. Tomato concentrate contained up to $31.0 \mu \mathrm{g} / \mathrm{kg} \mathrm{AOH}, 6.10 \mu \mathrm{g} / \mathrm{kg}$ AME, and $174.3 \mu \mathrm{g} / \mathrm{kg}$ TA (Walravens et al., 2016).

\section{Risk Evaluation}

A solid risk assessment on Alternaria mycotoxins is still not feasible, as toxicological and occurrence data on the toxins are insufficient. Therefore, the TTC approach was applied for $\mathrm{AOH}$, AME, TEN, and TA. For TEN and TA, the TTC level was set to $1500 \mathrm{ng} / \mathrm{kg}$ body weight per day (EFSA, 2011). In 2016, Rychlik et al. evaluated the exposure and risk to infants based on the consumption of millet based infant food (Rychlik et al., 2016). In their study, millet based infant food products were contaminated with TA with contents up to $1200 \mu \mathrm{g} / \mathrm{kg}$. Rychlik et al. calculated an intake of TA of $3670 \mathrm{ng} / \mathrm{kg}$ body weight upon consumption of the highly contaminated millet product. A maximum limit of TA in infant food products of $500 \mu \mathrm{g} / \mathrm{kg}$ was claimed so that the daily exposure of infants would fall below the TTC of $1500 \mathrm{ng} / \mathrm{kg}$ body weight per day for TA (EFSA, 2011; Rychlik et al., 2016). In the study presented here, all cereal based infant food samples contained TA below $500 \mu \mathrm{g} / \mathrm{kg}$ and, therefore, the products comply with this limit set by Rychlik et al. (2016).

Due to their genotoxicity, the TTC levels for AOH and AME were set to $2.5 \mathrm{ng} / \mathrm{kg}$ body weight per day (EFSA, 2011). One spelt product in our survey contained $7.17 \mu \mathrm{g} / \mathrm{kg} \mathrm{AOH}$. Considering an infant's weight of $7 \mathrm{~kg}$ and the size of a portion of $18 \mathrm{~g}$, as suggested by the manufacturer, the intake would be $18.4 \mathrm{ng} / \mathrm{kg}$ body weight. This exceeds the TTC value by a factor of around seven. Therefore, a risk to the health of the infant cannot be excluded. One millet, and two multi-grain samples contained $1.01,3.40$, and $1.37 \mu \mathrm{g} / \mathrm{kg}$ of $\mathrm{AOH}$, respectively. Calculating the intake of $\mathrm{AOH}$ based on the portions size of 20 to $25 \mathrm{~g}$, the intakes also exceed the TTC value of $2.5 \mathrm{ng} / \mathrm{kg}$. Considering the mean content of $\mathrm{AOH}$ of $0.89 \mu \mathrm{g} / \mathrm{kg}$ from our limited survey, the respective intake would not exceed the TTC level of $2.5 \mathrm{ng} / \mathrm{kg}$ 
body weight per day (EFSA, 2011). Moreover, the determined contents of AME and TEN in the cereal based infant food products were rather low and cannot be considered as a risk to the health of infants.

As further infant foods, four purees in jars and two tomato products were analyzed for mycotoxin contamination. Especially the tomato sauce contained high amounts of AOH, AME, TEN, and TA. Considering the size of a portion of $50 \mathrm{~g}$ and an infant's weight of $10 \mathrm{~kg}$ at the age of 12 months, the intake exceeds the TTC levels of AOH and AME many times over. Therefore, for this individual product, a risk to the health of infants cannot be excluded (EFSA, 2011) and we called the manufacturer's attention to this contamination. The median contents of the purees and tomato products were $0.32 \mu \mathrm{g} / \mathrm{kg}$ for $\mathrm{AOH}, 0.14 \mu \mathrm{g} / \mathrm{kg}$ for AME and $2.51 \mu \mathrm{g} / \mathrm{kg}$ for TA. On the basis of these calculations, the consumption of the infant food products do not constitute a risk to the health of the infants on average (EFSA, 2011).

Not only the free forms of the Alternaria mycotoxins attract the interest in quantitative analysis, but also the modified forms of $\mathrm{AOH}$ and $\mathrm{AME}$ are more frequently analyzed. Puntscher et al. quantitated the $\mathrm{AOH}$-9-glucoside and the $\mathrm{AOH}-3$-sulfate and AME-3-sulfate in food samples above the respective limits of quantification for the first time. Due to these modified forms of Alternaria mycotoxins, human health might be much more endangered than assumed and should be considered for tolerable daily intake determination (Puntscher et al., 2018). Further studies are underway to include also these toxins into our validated method.

\section{CONCLUSION}

A LC-MS/MS method for the simultaneous determination of six Alternaria mycotoxins was developed and the extraction and purification of mycotoxins was optimized. The method was validated successfully according to Vogelgesang and Hädrich (1998). The method validation was performed in starch and tomato matrix and resulted in low LODs and LOQs and good recoveries for all analytes. Good precisions confirmed stability and robustness of the method.

\section{REFERENCES}

Arcella, D., Eskola, M., and Gómez Ruiz, J. A. (2016). Dietary exposure assessment to Alternaria toxins in the European population. EFSA J. 14:4654. doi: 10.2903/ j.efsa.2016.4654

Arntzen, C. J. (1972). Inhibition of photophosphorylation by tentoxin, a cyclic tetrapeptide. Biochim. Biophys. Acta Bioenerg. 283, 539-542. doi: 10.1016/00052728(72)90273-3

Asam, S., Konitzer, K., and Rychlik, M. (2011a). Precise determination of the Alternaria mycotoxins alternariol and alternariol monomethyl ether in cereal, fruit and vegetable products using stable isotope dilution assays. Mycotoxin Res. 27, 23-28. doi: 10.1007/s12550-010-0071-6

Asam, S., Konitzer, K., Schieberle, P., and Rychlik, M. (2009). Stable isotope dilution assays of alternariol and alternariol monomethyl ether in beverages. J. Agric. Food Chem. 57, 5152-5160. doi: 10.1021/jf90 0450w
Various cereal based infant foods, jars containing vegetables and fruits and tomato based products for infants were analyzed for Alternaria mycotoxins. Studies on infant foods are rare and so far were limited to certain toxins (Scott et al., 2012; Asam and Rychlik, 2013). Our study included six toxins in the analysis of infant foods for the first time. The analyses resulted in partly high contaminations of the infant food products and risks to the health of infants cannot be excluded. These new and unexpected results show that more infant food products should be analyzed to determine mycotoxin contamination and to perform a proper risk assessment with special regards to infants. Moreover, the manufacturers should be made aware of the necessity to screen their products more thoroughly for these toxins and take the appropriate measures to reduce their contents.

\section{AUTHOR CONTRIBUTIONS}

SA, MG, and MR designed the experiments. KG optimized the mycotoxin extraction and purification and performed the method validation for starch matrix. RK optimized analyte purification by solid phase extraction. AM performed the method validation for tomato matrix. EB analyzed the infant food samples. MG and SA wrote the manuscript. MR revised the manuscript. All authors contributed to the revision of the manuscript.

\section{FUNDING}

This work was supported by the German Research Foundation (DFG) and the Technical University of Munich (TUM) in the framework of the Open Access Publishing Program.

\section{ACKNOWLEDGMENTS}

The authors appreciate the valuable practical assistance by Christopher Zeck and Martin Neumeier.

Asam, S., Lichtenegger, M., Liu, Y., and Rychlik, M. (2012). Content of the Alternaria mycotoxin tenuazonic acid in food commodities determined by a stable isotope dilution assay. Mycotoxin Res. 28, 9-15. doi: 10.1007/s12550-0110111-x

Asam, S., Lichtenegger, M., Muzik, K., Liu, Y., Frank, O., Hofmann, T., et al. (2013). Development of analytical methods for the determination of tenuazonic acid analogues in food commodities. J. Chromatogr. A 1289, 27-36. doi: 10.1016/j. chroma.2013.03.015

Asam, S., Liu, Y., Konitzer, K., and Rychlik, M. (2011b). Development of a stable isotope dilution assay for tenuazonic acid. J. Agric. Food Chem. 59, 2980-2987. doi: 10.1021/jf104270e

Asam, S., and Rychlik, M. (2013). Potential health hazards due to the occurrence of the mycotoxin tenuazonic acid in infant food. Eur. Food Res. Technol. 236, 491-497. doi: 10.1007/s00217-012-1901-x

Asam, S., and Rychlik, M. (2015). Recent developments in stable isotope dilution assays in mycotoxin analysis with special regard to Alternaria 
toxins. Anal. Bioanal. Chem. 407, 7563-7577. doi: 10.1007/s00216-0158904-y

Berardis, S., de, Paola, E. L., de Montevecchi, G., Garbini, D., Masino, F., et al. (2018). Determination of four Alternaria alternata mycotoxins by QuEChERS approach coupled with liquid chromatography-tandem mass spectrometry in tomato-based and fruit-based products. Food Res. Int. 106, 677-685. doi: 10. 1016/j.foodres.2018.01.032

Brugger, E.-M., Wagner, J., Schumacher, D. M., Koch, K., Podlech, J., Metzler, M., et al. (2006). Mutagenicity of the mycotoxin alternariol in cultured mammalian cells. Toxicol. Lett. 164, 221-230. doi: 10.1016/j.toxlet.2006.01.001

EFSA (2011). Scientific opinion on the risks for animal and public health related to the presence of Alternaria toxins in feed and food. EFSA J. 9:2407. doi: 10.2903/j.efsa.2011.2407

Fehr, M., Pahlke, G., Fritz, J., Christensen, M. O., Boege, F., Altemöller, M., et al. (2009). Alternariol acts as a topoisomerase poison, preferentially affecting the II $\alpha$ isoform. Mol. Nutr. Food Res. 53, 441-451. doi: 10.1002/mnfr.200700379

Fleck, S. C., Burkhardt, B., Pfeiffer, E., and Metzler, M. (2012). Alternaria toxins: altertoxin II is a much stronger mutagen and DNA strand breaking mycotoxin than alternariol and its methyl ether in cultured mammalian cells. Toxicol. Lett. 214, 27-32. doi: 10.1016/j.toxlet.2012.08.003

Fleck, S. C., Sauter, F., Pfeiffer, E., Metzler, M., Hartwig, A., and Köberle, B. (2016). DNA damage and repair kinetics of the Alternaria mycotoxins alternariol, altertoxin II and stemphyltoxin III in cultured cells. Mutation research. Genet. Toxicol. Environ. Mutagenesis 798-799, 27-34. doi: 10.1016/j.mrgentox.2016.02. 001

Jarolim, K., Del Favero, G., Ellmer, D., Stark, T. D., Hofmann, T., Sulyok, M., et al. (2016). Dual effectiveness of Alternaria but not Fusarium mycotoxins against human topoisomerase II and bacterial gyrase. Arch. Toxicol. 91, 2007-2016. doi: 10.1007/s00204-016-1855-Z

Kang, Y., Feng, H., Zhang, J., Chen, S., Valverde, B. E., and Qiang, S. (2017). TeA is a key virulence factor for Alternaria alternata (Fr.) Keissler infection of its host. Plant Physiol. Biochem. 115, 73-82. doi: 10.1016/j.plaphy.2017.03.002

Kroes, R., Renwick, A., Cheeseman, M., Kleiner, J., Mangelsdorf, I., Piersma, A., et al. (2004). Structure-based thresholds of toxicological concern (TTC): guidance for application to substances present at low levels in the diet. Food Chem. Toxicol. 42, 65-83. doi: 10.1016/j.fct.2003.08.006

Liu, Y., and Rychlik, M. (2013). Development of a stable isotope dilution LCMS/MS method for the Alternaria toxins tentoxin, dihydrotentoxin, and isotentoxin. J. Agric. Food Chem. 61, 2970-2978. doi: 10.1021/jf305111w

Liu, Y., and Rychlik, M. (2015). Biosynthesis of seven carbon-13 labeled Alternaria toxins including altertoxins, alternariol, and alternariol methyl ether, and their application to a multiple stable isotope dilution assay. Anal. Bioanal. Chem. 407, 1357-1369. doi: 10.1007/s00216-014-8307-5

Logrieco, A., Moretti, A., and Solfrizzo, M. (2009). Alternaria toxins and plant diseases: an overview of origin, occurrence and risks. World Mycotoxin J. 2, 129-140. doi: 10.3920/WMJ2009.1145

Lohrey, L., Marschik, S., Cramer, B., and Humpf, H.-U. (2013). Large-scale synthesis of isotopically labeled 13c2-tenuazonic acid and development of a rapid HPLC-MS/MS method for the analysis of tenuazonic acid in tomato and pepper products. J. Agric. Food Chem. 61, 114-120. doi: 10.1021/jf305138k

Malachová, A., Sulyok, M., Beltrán, E., Berthiller, F., and Krska, R. (2014). Optimization and validation of a quantitative liquid chromatography-tandem mass spectrometric method covering 295 bacterial and fungal metabolites including all regulated mycotoxins in four model food matrices. J. Chromatogr. A 1362, 145-156. doi: 10.1016/j.chroma.2014.08.037

Miller, F. A., Rightsel, W. A., Sloan, B. J., Ehrlich, J., French, J. C., and Bartz, Q. R. (1963). Antiviral activity of tenuazonic acid. Nature 200, 1338-1339. doi: $10.1038 / 2001338 \mathrm{a} 0$

Noser, J., Schneider, P., Rother, M., and Schmutz, H. (2011). Determination of six Alternaria toxins with UPLC-MS/MS and their occurrence in tomatoes and tomato products from the Swiss market. Mycotoxin Res. 27, 265-271. doi: 10.1007/s12550-011-0103-x

Ostry, V. (2008). Alternaria mycotoxins. An overview of chemical characterization, producers, toxicity, analysis and occurrence in foodstuffs. World Mycotoxin J. 1, 175-188. doi: 10.3920/WMJ2008.x013

Ozcelik, S., Ozcelik, N., and Beuchat, L. R. (1990). Toxin production by Alternaria alternata in tomatoes and apples stored under various conditions and quantitation of the toxins by high-performance liquid chromatography. Int. J. Food Microbiol. 11, 187-194. doi: 10.1016/0168-1605(90) 90011-S
Prelle, A., Spadaro, D., Garibaldi, A., and Gullino, M. L. (2013). A new method for detection of five Alternaria toxins in food matrices based on LC-APCI-MS. Food Chem. 140, 161-167. doi: 10.1016/j.foodchem.2012.12.065

Puntscher, H., Kütt, M.-L., Skrinjar, P., Mikula, H., Podlech, J., Fröhlich, J., et al. (2018). Tracking emerging mycotoxins in food: development of an LC-MS/MS method for free and modified Alternaria toxins. Anal. Bioanal. Chem. 410, 4481-4494. doi: 10.1007/s00216-018-1105-8

Rodríguez-Carrasco, Y., Mañes, J., Berrada, H., and Juan, C. (2016). Development and validation of a LC-ESI-MS/MS method for the determination of Alternaria toxins alternariol, alternariol methyl-ether and tentoxin in tomato and tomatobased products. Toxin 8:E328. doi: 10.3390/toxins 8110328

Rychlik, M., and Asam, S. (2008). Stable isotope dilution assays in mycotoxin analysis. Anal. Bioanal. Chem. 390, 617-628. doi: 10.1007/s00216-007-1717-x

Rychlik, M., Humpf, H.-U., Marko, D., Dänicke, S., Mally, A., Berthiller, F., et al. (2014). Proposal of a comprehensive definition of modified and other forms of mycotoxins including "masked" mycotoxins. Mycotoxin Res. 30, 197-205. doi: 10.1007/s12550-014-0203-5

Rychlik, M., Lepper, H., Weidner, C., and Asam, S. (2016). Risk evaluation of the Alternaria mycotoxin tenuazonic acid in foods for adults and infants and subsequent risk management. Food Control 68, 181-185. doi: 10.1016/j. foodcont.2016.03.035

Schwarz, C., Tiessen, C., Kreutzer, M., Stark, T., Hofmann, T., and Marko, D. (2012). Characterization of a genotoxic impact compound in Alternaria alternata infested rice as Altertoxin II. Arch. Toxicol. 86, 1911-1925. doi: 10. 1007/s00204-012-0958-4

Scott, P. M., Zhao, W., Feng, S., and Lau, B. P.-Y. (2012). Alternaria toxins alternariol and alternariol monomethyl ether in grain foods in Canada. Mycotoxin Res. 28, 261-266. doi: 10.1007/s12550-012-0141-z

Shephard, G. S., Thiel, P. G., Sydenham, E. W., Vleggaar, R., and Marasas, W. (1991). Reversed-phase high-performance liquid chromatography of tenuazonic acid and related tetramic acids. J. Chromatogr. B Biomed. Sci. Appl. 566, 195-205. doi: 10.1016/0378-4347(91)80124-U

Shigeura, H. T., and Gordon, C. N. (1963). The biological activity of tenuazonic acid*. Biochemistry 2, 1132-1137. doi: 10.1021/bi00905a039

Siegel, D., Rasenko, T., Koch, M., and Nehls, I. (2009). Determination of the Alternaria mycotoxin tenuazonic acid in cereals by high-performance liquid chromatography-electrospray ionization ion-trap multistage mass spectrometry after derivatization with 2,4-dinitrophenylhydrazine. J. Chromatogr. A 1216, 4582-4588. doi: 10.1016/j.chroma.2009.03.063

Smith, E. R., Fredrickson, T. N., and Hadidian, Z. (1968). Toxic effects of the sodium and the N,N'-dibenzylethylenediamine salts of tenuazonic acid. Cancer Chemother. Rep. 52, 579-585.

Soukup, S. T., Kohn, B. N., Pfeiffer, E., Geisen, R., Metzler, M., Bunzel, M., et al. (2016). Sulfoglucosides as novel modified forms of the mycotoxins alternariol and alternariol monomethyl ether. J. Agric. Food Chem. 64, 8892-8901. doi: 10.1021/acs.jafc.6b03120

Stack, M. E., and Prival, M. J. (1986). Mutagenicity of the Alternaria metabolites altertoxins I, II and III. Appl. Environ. Microbiol. 52, 718-722.

Vogelgesang, J., and Hädrich, J. (1998). Limits of detection, identification and determination: a statistical approach for practitioners. Accredit Qual. Assur. 3, 242-255. doi: 10.1007/s007690050234

Walravens, J., Mikula, H., Rychlik, M., Asam, S., Devos, T., Njumbe Ediage, E., et al. (2016). Validated UPLC-MS/MS methods to quantitate free and conjugated Alternaria toxins in commercially available tomato products and fruit and vegetable juices in Belgium. J. Agric. Food Chem. 64, 5101-5109. doi: 10.1021/ acs.jafc.6b01029

Walravens, J., Mikula, H., Rychlik, M., Asam, S., Ediage, E. N., Di Mavungu, J. D., et al. (2014). Development and validation of an ultra-high-performance liquid chromatography tandem mass spectrometric method for the simultaneous determination of free and conjugated Alternaria toxins in cereal-based foodstuffs. J. Chromatogr. A 1372, 91-101. doi: 10.1016/j.chroma.2014.10.083

Zwickel, T., Kahl, S. M., Rychlik, M., and Müller, M. E. H. (2018). Chemotaxonomy of mycotoxigenic small-spored Alternaria fungi - do multitoxin mixtures act as an indicator for species differentiation? Front. Microbiol. 9:1368. doi: 10.3389/ fmicb.2018.01368

Zwickel, T., Klaffke, H., Richards, K., and Rychlik, M. (2016). Development of a high performance liquid chromatography tandem mass spectrometry based analysis for the simultaneous quantification of various Alternaria toxins in wine, vegetable juices and fruit juices. J. Chromatogr. A 1455, 74-85. doi: 10. 1016/j.chroma.2016.04.066 
Conflict of Interest Statement: The authors declare that the research was conducted in the absence of any commercial or financial relationships that could be construed as a potential conflict of interest.

The reviewer BŠ declared a past co-authorship with one of the authors MR to the handling editor.
Copyright (C) 2019 Gotthardt, Asam, Gunkel, Moghaddam, Baumann, Kietz and Rychlik. This is an open-access article distributed under the terms of the Creative Commons Attribution License (CC BY). The use, distribution or reproduction in other forums is permitted, provided the original author(s) and the copyright owner(s) are credited and that the original publication in this journal is cited, in accordance with accepted academic practice. No use, distribution or reproduction is permitted which does not comply with these terms. 